\title{
Shear Strength of Adhesive Lamination Joint of Aluminum and CFRP Sheets Treated by Homogeneous Low Energy Electron Beam Irradiation Prior to Lamination Assembly and Hot-Press
}

\author{
Takumi Okada ${ }^{1, *}$, Masae Kanda ${ }^{1,2}$, Michael C. Faudree ${ }^{2}$ and Yoshitake Nishi ${ }^{1,2}$ \\ ${ }^{1}$ Graduate School of Engineering, Tokai University, Hiratsuka 259-1292, Japan \\ ${ }^{2}$ Department of Materials Science, Tokai University, Hiratsuka 259-1292, Japan
}

Adhesive 2-layer lamination joint of aluminum/carbon fiber reinforced epoxy polymer (Al/CFRP) were prepared by a new adhesion method, a double-step treatment consisting of applying low dose $(=0.22 \mathrm{MGy})$ of homogeneous low energy electron beam irradiation (HLEBI) to the CFRP and Al prior to lamination assembly and hot-press in vacuum below $1 \mathrm{~Pa}$ for $2 \mathrm{~h}$ at $403 \mathrm{~K}$. No fasteners or external adhesives were applied: the cured epoxy enhanced by the HLEBI acts as the adhesive to the Al. The new treatment apparently boosted shear strength ( $\tau$ ) of the $\mathrm{Al} / \mathrm{CFRP} 45 \%$ at low shear strength probability $\left(P_{\mathrm{s}}=0.06\right)$ at $0.22 \mathrm{MGy}$. XPS (X-ray photoelectron spectrometry) measurements detected carbon on the shear fractured Al interface indicating the residual epoxy adhered well to the Al by the HLEBI. This is probably a result of adhesion force of Al/CFRP being made stronger than the cohesive force of epoxy polymer in the CFRP itself. When HLEBI cuts the chemical bonds and generates active terminated atoms with dangling bonds in epoxy polymer, the nonbonding electrons probably induced the chemical bonding and intermolecular coulomb attractive forces at the interface. Hence, the increased adhesion force in the Al/CFRP joint can be explained. [doi:10.2320/matertrans.MAW201419]

(Received April 28, 2014; Accepted August 5, 2014; Published September 12, 2014)

Keywords: joint, aluminum, carbon fiber reinforced epoxy polymer (CFRP), shear strength, electron beam

\section{Introduction}

Techniques to increase the strength of metal/composite joints are highly sought after. Aluminum joined with CFRP for structural applications has been widely utilized in the aerospace, automotive and shipbuilding industries, along with various day-to-day articles. Carbon fiber reinforced epoxy polymer (CFRP) with its high strength to weight ratio along with aluminum (Al) with its high electrical conductivity, shiny silver color, light specific weight and high corrosion resistance due to passivation are valuable light structural materials utilized for aerospace technology with high specific strength. ${ }^{1,2)}$

It is always important to develop a joint with maximum safety enhancement adding minimal weight to the structure for low energy consumption with concern for the environment. However, methods of joining two different materials such as fasteners including bolts and rivets; and adhesive bonding articles such as welding and soldering, has always been some of the serious problems to decay the materials.

While advantages of fasteners are simple processing, high joining strength, and small scatter in the data, disadvantages include increase in weight due to the fasteners and low sealing performance. Moreover the bolt holes decrease the cross-sectional area and can act as stress concentrators. It is reported drilling holes in FRP laminate composites results in breakage of the reinforcing fibers, peeling of the top plies at hole entry, resin degradation at the hole wall, and delamination of the bottom plies of the laminates. ${ }^{3,4)}$ The resulting damage can result in generation of fatigue cracks during fatigue. ${ }^{5)}$

For adhesive bonding articles, advantages are complete sealing effect, parts are lighter since fasteners are not used, hence no stress concentration due to the bolt hole and no damage due to drilling therefore they typically exhibit higher fatigue strength than bolted joints. ${ }^{5)}$ However, disadvantages include adhesion selection is difficult for joints of different materials, additional steps of degreasing and etching the adhering surfaces are needed to obtain high adhesion strength, and chemically treated adhesive joints have the disadvantage of degradation after a few hours by oxidation decreasing bonding strength. ${ }^{6)}$ Due to these constraints, high strength adhesive joints are difficult to attain.

However, an Al/CFRP joint was developed without the use of fasteners, chemical treatment, or external adhesive by a new adhesion method, a double-step treatment consisting of applying low dose $(=0.22 \mathrm{MGy})$ of homogeneous low energy electron beam irradiation (HLEBI) to the CFRP and $\mathrm{Al}$ prior to lamination assembly and hot-press which apparently boosted shear strength $(\tau)$ of the Al/CFRP joint $29 \%$ at middle shear strength probability over the untreated.

HLEBI has a successful track record for improving many materials. $^{7-14)}$ HLEBI is reported to improve the mist resistance and wetting of materials, ${ }^{7-10)}$ and increases polymer adhering to fibers raising impact strength in GFRP. ${ }^{11,12)}$ These effects are mainly caused by surface energy induced by the irradiation with the formation of active terminated atoms with dangling bonds. When HLEBI improves the joining between different polymers and metals/polymers, ${ }^{13,14)}$ rapid and safety adhesion between different polymers by using HLEBI has been successfully developed. Figure 1 exhibits the shear test sample of $\mathrm{Al} / \mathrm{CFRP}$ adhesive lamination joint suggested. For this reason, the effects of HLEBI prior to lamination assembly and hot-press lamination on the shear strength of adhesive $\mathrm{Al} / \mathrm{CFRP}$ laminated joints of $\mathrm{Al}$ and CFRP have been investigated. 


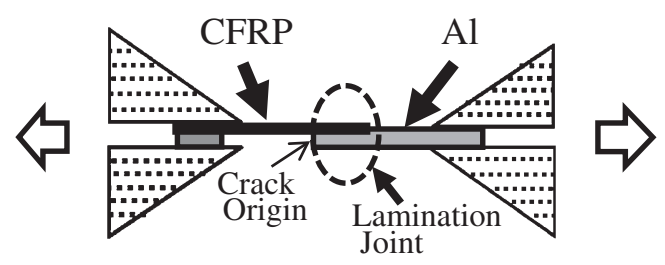

Fig. 1 Schematic drawing of shear testing sample.

\section{Experimental Procedure}

\subsection{Preparation of Al/CFRP}

Composite sheets were constructed with $\mathrm{Al}(10 \mathrm{~mm} \times$ $40 \mathrm{~mm} \times 2.0 \mathrm{~mm}$, Taiho trading Co., LTD.); and CFRP $(10 \mathrm{~mm} \times 40 \mathrm{~mm} \times 0.25 \mathrm{~mm})(1$ ply $0.25 \mathrm{~mm}$ in thickness $)$.

Volume of carbon fiber cross textile reinforced epoxy polymer composite (CFRP; TR3110-331MP epoxy/CF, Mitsubishi Rayon Ltd., Tokyo) was $0.25 \times 40 \times 10=$ $100 \mathrm{~mm}^{3}$ with adhesive area $\left(10 \times 10=100 \mathrm{~mm}^{2}\right)$ for tensile shear test. In the CFRP sheet, $V_{\mathrm{f}}$ of carbon fiber was $60 \%$.

Specifically, the preparation steps of the Al/CFRP joint samples were as follows. Step 1 is the Al and CFRP prepreg were cut to size. Step 2 is the novel part of the process, homogeneous low-voltage electron beam (HLEBI) treatment was applied to the joining surfaces of the Al and CFRP (see section 2.2) prior to lamination assembly. Step 3 is the CFRP and $\mathrm{Al}$ were assembled. Step 4 is the $\mathrm{Al} / \mathrm{CFRP}$ assembly was inserted into a hot press in vacuum below $1 \mathrm{~Pa}$ for $2 \mathrm{~h}$ at $403 \mathrm{~K}$ to cure the CFRP to adhere with the Al producing the laminated joint samples. No fasteners or external adhesives were applied: the cured epoxy enhanced by the HLEBI acts as the adhesive to the Al.

\subsection{Homogeneous low voltage electron beam irradiation (HLEBI)}

To aim for high reproducibility of shear strength results, the connecting surfaces of the Al and CFRP sheets were homogeneously irradiated by an electron-curtain processor (Type CB175/15/180L, Energy Science Inc., Woburn, MA, Iwasaki Electric Group Co., Ltd., Tokyo). ${ }^{15-18)}$ The samples were homogeneously irradiated with an electron beam through a titanium window attached to a $24 \mathrm{~cm}$-diameter vacuum chamber. A tungsten filament in a vacuum was used to generate the electron beam with an electric voltage of $0.17 \mathrm{MeV}$ and an irradiating current of $2.0 \mathrm{~mA}$. To prevent oxidation, the samples were kept in a nitrogen atmosphere of $0.10 \mathrm{MPa}$ with a residual oxygen concentration of less than $0.040 \%$. The flow rate of the nitrogen gas was $1.5 \mathrm{~L} / \mathrm{s}$.

Given the densities $(\rho)$ are $2.7 \mathrm{~g} \cdot \mathrm{cm}^{-3}$ for $\mathrm{Al}, 1.76 \mathrm{~g} \cdot \mathrm{cm}^{-3}$ for carbon fiber and $1.20 \mathrm{~g} \cdot \mathrm{cm}^{-3}$ for epoxy, the penetration depth $\left(D_{\text {th }}\right)$ values of $0.080 \mathrm{~mm}$ for $\mathrm{Al}, 0.123 \mathrm{~mm}$ for carbon fiber and $0.180 \mathrm{~mm}$ for epoxy were estimated by assumptions of Christenhusz and Reimer, respectively. ${ }^{19,20)}$ Namely, the effective depth of homogeneous irradiation was $0.080 \mathrm{~mm}$ for $\mathrm{Al}$ and $0.135 \mathrm{~mm}$ for CFRP. Consequently, since the irradiated thickness values of laminated composites with $\mathrm{Al}$ and CFRP were $2000 \mu \mathrm{m}$ and $250 \mu \mathrm{m}$, the adhesive interface is perfectly irradiated with sufficient thicknesses. After the HLEBI the Al/CFRP composite sheet lamination was performed by the hot-press.

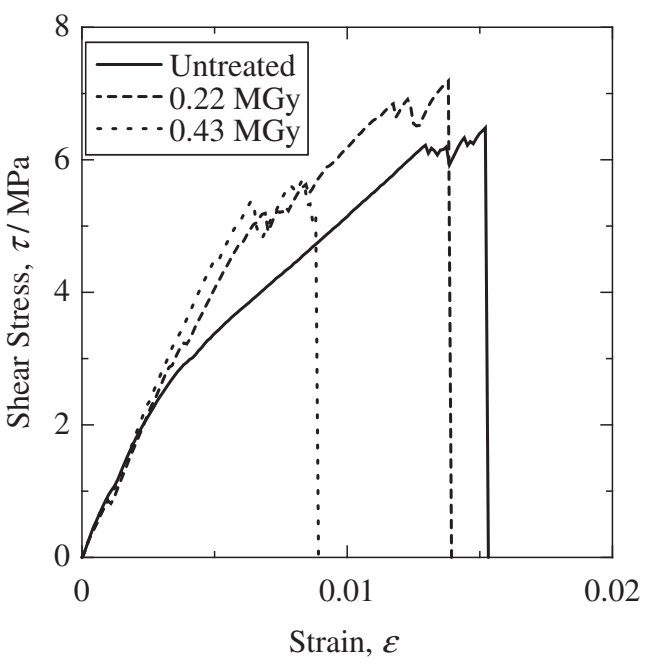

Fig. 2 Shear stress-strain curves at mid cumulative probability of shear strength $\left(P_{\mathrm{s}}=0.50\right)$ of $\mathrm{Al} / \mathrm{CFRP}$ lamination joints with and without HLEBI of 0.22 and $0.43 \mathrm{MGy}$.

\subsection{Tensile shear strength}

Tensile shear strength tests were performed by an Instron type tensile machine at a constant strain rate of $1 \mathrm{~mm} / \mathrm{min}$ on the samples as illustrated in Fig. 1 where the joint was pulled in tension, a shim being added with the thin CFRP sheet in the grips. The $\operatorname{stress}(\tau)$-strain $(\varepsilon)$ curves were obtained where shear strength $\left(\tau_{\mathrm{B}}\right)$ is defined at the maximum shear stress.

\subsection{Shear strength probability}

The cumulative probability $(P)$ by the median rank method $^{21)}$ often employed in quality control (QC) is one of the widely used and convenient ways to analyze mechanical probabilities of adhesive strength, ${ }^{22)}$ adhesive peeling resistance, ${ }^{23)}$ and other mechanical properties. ${ }^{24-30)}$ Likewise, evaluating the shear strength probability $\left(P_{\mathrm{s}}\right)$ is also a convenient method and is used in quantitatively analyzing experimental values relating to peeling resistance. ${ }^{20)} P_{\mathrm{S}}$ is expressed by the following equation:

$$
P_{\mathrm{s}}=(I-0.3) /(n+0.4)
$$

Here, $n$ and $I$ are total number of samples $(n=11)$ and rank order of shear strength of each sample from weakest to strongest $(1 \leqq I \leqq 11)$, respectively. When the $I$ values are 1,6 , and 11 , the $P_{\mathrm{s}}$ values are $0.06,0.50$ and 0.94 , respectively.

\section{Results}

Figure 2 depicts the shear stress $(\tau)$-strain $(\varepsilon)$ curves at median cumulative probability of shear strength $\left(P_{\mathrm{s}}=0.50\right)$ of $\mathrm{Al} / \mathrm{CFRP}$ lamination joints for the three conditions: 0.22 and 0.43 MGy HLEBI treated prior to lamination assembly and hot-press, along with the untreated. Although 0.43 MGyHLEBI slightly decays the shear strength $\left(\tau_{\mathrm{B}}\right)$, it tremendously decreases the shear strain $\left(\varepsilon_{\mathrm{B}}\right)$ as typical radiation damage when HLEBI dose is too high.

Although the joints with and without 0.22 and $0.43 \mathrm{MGy}$ exhibit the same initial stiffness, that is, shear resistance up to 0.003 of strain, HLEBI with 0.22 and $0.43 \mathrm{MGy}$ enhances the 


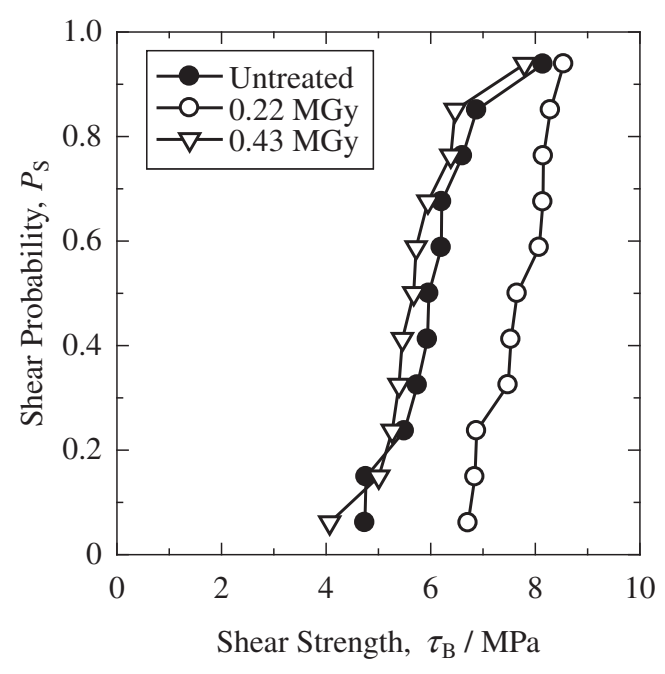

Fig. 3 Changes in shear strength $\left(\tau_{\mathrm{B}}\right)$ of of $\mathrm{Al} / \mathrm{CFRP}$ lamination joints with and without HLEBI with 0.22 and $0.43 \mathrm{MGy}$ against cumulative probability of shear strength $\left(P_{\mathrm{s}}\right)$.

stiffness from 0.003 of strain to $\varepsilon_{\mathrm{B}}$. Namely, hardening is induced by HLEBI below $0.43 \mathrm{MGy}$, although HLEBI to $0.43 \mathrm{MGy}$ always decays the $\varepsilon_{\mathrm{B}}$ of the joint.

On the other hand, 0.22 MGy-HLEBI remarkably enhances the $\tau_{\mathrm{B}}$, although it slightly decays the $\varepsilon_{\mathrm{B}}$.

Figure 3 shows applying the 0.22 MGy-HLEBI prior to lamination assembly and hot-press apparently improves the $\tau_{\mathrm{B}}$ values of $\mathrm{Al} / \mathrm{CFRP}$ at all $P_{\mathrm{s}}$. The plot in Fig. 3 shows the changes in shear strength $\left(\tau_{\mathrm{B}}\right)$ of $\mathrm{Al} / \mathrm{CFRP}$ lamination joints for the three conditions against cumulative probability of shear strength $\left(P_{\mathrm{s}}\right)$.

The additional dose of $0.43 \mathrm{MGy}-\mathrm{HLEBI}$ decreases the $\tau_{\mathrm{B}}$ values, slightly below those of the untreated at almost all $P_{\mathrm{s}}$, therefore carefulness is recommended to adjust for the optimum HLEBI dose in industry.

\section{Discussion}

Fracture sites generally occurred at the interface of the 2-layer assembled $\mathrm{Al} / \mathrm{CFRP}$ lamination joint. When HLEBI creates increased adhesion at $\mathrm{Al} / \mathrm{CFRP}$ interface, residual epoxy deposition is retained on the $\mathrm{Al}$ sheet by intermatrix fracture of epoxy resin further into the CFRP thickness near the carbon fibers. X-ray photoelectron spectrometry (XPS: Quantum 2000, ULVAC Co., JAPAN) measurements detected carbon on the shear fractured $\mathrm{Al}$ interface indicating the residual epoxy adhered well to the $\mathrm{Al}$ by the HLEBI.

Although remarkable ESR signals could not be detected in either the untreated epoxy in CFRP, ESR signals, indicating dangling bond formation, in fact have been observed in epoxy film treated by HLEBI. ${ }^{31)}$ When HLEBI cuts the chemical bonds and generates active terminated atoms with dangling bonds in epoxy polymer, the nonbonding electrons probably induce the chemical bonding and intermolecular coulomb attractive forces at the interface. The adhesive force at the Al/CFRP sheets by applying HLEBI prior to lamination assembly and hot-press lamination can therefore be explained.

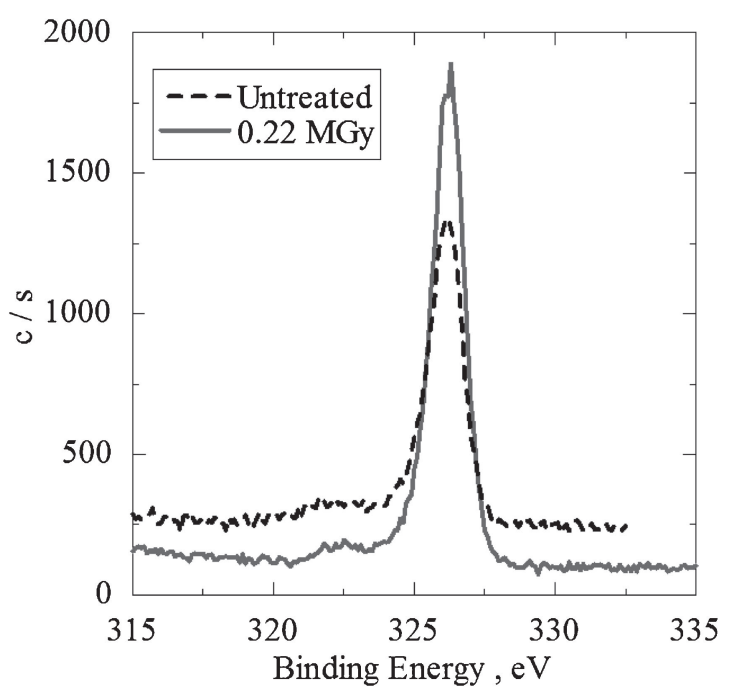

Fig. 4 Carbon (1s) signal in Al side of XPS analysis of CFRP-Al laminated films with and without HLEBI.

The epoxy in CFRP is composed of hydrogen $(\mathrm{H})$, carbon $(\mathrm{C})$, nitrogen $(\mathrm{N})$ and Oxygen $(\mathrm{O})$. Figure 4 illustrates carbon (1s) signal from the peeled Al surface by XPS surface analysis of $\mathrm{Al} / \mathrm{CFRP}$ laminated films with and without HLEBI treatment. Based on the results, carbon is found on the shear fractured Al surface after HLEBI (see Fig. 4). In comparison, a smaller signal can be observed in the untreated sample, laminated by hot-press but not HLEBI treated. When the adhesion force of Al/CFRP by HLEBI prior to lamination assembly and hot-press is stronger than the cohesive force of epoxy polymer in the CFRP itself, XPS detecting residual epoxy deposition as a higher intensity carbon peak on the $\mathrm{Al}$ sheet can be explained.

From the treatment applying HLEBI, electrons probably induce polarization at terminated atoms of the Al and CFRP at the adhesive interface creating adhesion. At increased dose of $0.22 \mathrm{MGy}$, the dangling bond density appears to be at or near the optimum for maximum adhesive force.

On the other hand, carefulness must be considered in design since higher dangling bond densities occur from the treatment applying HLEBI doses greater than 0.22 MGy acting as crack origins and propagation sites in epoxy resin near the laminated interface between $\mathrm{Al}$ and CFRP, degrading the polymers and reducing $\tau_{\mathrm{B}}$ (see Fig. 4). Therefore, with cautious consideration to dose level, the new treatment applying HLEBI prior to lamination assembly and hot press proves a viable method for quick lamination of $\mathrm{Al}$ and CFRP without the use of external adhesive or fasteners.

\section{Conclusion}

Up to now, the adhesion of 2-layer laminated Al/CFRP sheets without our treatment with hot-press after homogeneous low energy electron beam irradiation (HLEBI) has not been observed in the literature. However, strong adhesion of the Al/CFRP was created from the new treatment applying low dose $\leqq 0.43$ MGy homogeneous HLEBI to the CFRP and $\mathrm{Al}$ prior to lamination assembly and hot-press in vacuum below $1 \mathrm{~Pa}$ for $2 \mathrm{~h}$ at $403 \mathrm{~K}$. 
(1) This new treatment apparently boosted shear strength $(\tau)$ of the Al/CFRP joint $45 \%\left(P_{\mathrm{s}}=0.06\right)$ at $0.22 \mathrm{MGy}$. Although 0.43 MGy-HLEBI slightly decayed the shear strength $\left(\tau_{\mathrm{B}}\right)$, it tremendously decreased the shear strain $\left(\varepsilon_{\mathrm{B}}\right)$ as typical radiation damage. 0.22 MGy-HLEBI enhanced the $\tau_{\mathrm{B}}$, although it slightly decayed the $\varepsilon_{\mathrm{B}}$. HLEBI from 0.22 to $0.43 \mathrm{MGy}$ always reduced the $\varepsilon_{\mathrm{B}}$ of the joint.

Although by the slopes of the shear stress-strain curves the joints with and without 0.22 and $0.43 \mathrm{MGy}$ exhibited the same initial stiffness, i.e., shear resistance up to 0.003 of strain, HLEBI of 0.22 and $0.43 \mathrm{MGy}$ enhanced the stiffness from 0.003 of strain to $\varepsilon_{\mathrm{B}}$. Namely, hardening appeared to be induced by the HLEBI.

(2) Moreover, applying the 0.22 MGy-HLEBI apparently improved the $\tau_{\mathrm{B}}$ values of $\mathrm{Al} / \mathrm{CFRP}$ at all $P_{\mathrm{s}}$. On the other hand, the additional dose of $0.43 \mathrm{MGy}-\mathrm{HLEBI}$ decreased the $\tau_{\mathrm{B}}$ values, slightly below those of the untreated at almost all $P_{\mathrm{s}}$, therefore carefulness is recommended to adjust for the optimum HLEBI dose in industry.

(3) Surface analysis by XPS detected carbon on the shear fractured $\mathrm{Al}$ interface indicating the residual epoxy adhered well to the Al by the HLEBI. In comparison, a smaller signal was observed in the untreated sample, laminated by hot-press but not HLEBI treated. The increased peak intensity is probably a result of adhesion force of $\mathrm{Al} / \mathrm{CFRP}$ being made stronger than the cohesive force of epoxy polymer in the CFRP itself by the HLEBI.

(4) With careful consideration to optimize dose level, the new treatment applying HLEBI prior to lamination assembly and hot press proves a viable method for quick lamination of $\mathrm{Al}$ and epoxy CFRP without the use of external adhesives or fasteners.

\section{Acknowledgements}

The authors thank Prof. Akira Tonegawa of Tokai University for his useful help. Our sincere gratitude also goes to Eye Electron Beam Co., Ltd. (Gyoda, Saitama, Japan) for their support with this work.

\section{REFERENCES}

1) D. K. Thomas: Plastics Rubber Int. 8 (1983) 53-57.

2) M. B. Dowell: Plastics Eng. 33 (1977) 31-32.

3) R. Zitoune and F. Collombet: Compos. Part A 38 (2007) 858-866.

4) J. Davim, P. Reis and C. Antonio: Compos. Sci. Technol. 64 (2004) 289-297.

5) R. Matsuzaki, M. Shibata and A. Todoroki: Compos. Part A 39 (2008) 154-163.

6) K. Allen: Int. J. Adhes. 23 (2003) 87-93.

7) K. Oguri, N. Iwataka, A. Tonegawa, Y. Hirose, K. Takayama and Y. Nishi: J. Mater. Res. 16 (2001) 553-557.

8) K. Oguri, Y. Irisawa, A. Tonegawa and Y. Nishi: J. Intellig. Mater. Struct. 17 (2006) 761-765.

9) Y. Nishi, K. Oguri, K. Fujita, M. Takahashi, Y. Omori, A. Tonegawa, N. Honda, M. Ochi and K. Takayama: J. Mater. Res. 13 (1998) 33683371 .

10) K. Oguri, T. Takahashi, A. Kadowaki, A. Tonegawa and Y. Nishi: J. Japan Inst. Metals 68 (2004) 537-539.

11) Y. Nishi, H. Kobayashi and M. Salvia: Mater. Trans. 48 (2007) 19241927.

12) M. Faudree and Y. Nishi: Mater. Trans. 53 (2012) 1412-1419.

13) M. Uyama, N. Fujiyama, T. Okada, M. Kanda and Y. Nishi: Mater. Trans. 55 (2014) 561-565.

14) T. Shimaru: Technol. Adhes. Seal. 3 (1959) 121-130.

15) A. Kasashima, N. Iwataka, J. Kawano, N. Honda and Y. Nishi: J. Adv. Sci. 9 (1997) 70-71.

16) Y. Nishi, H. Sato, H. Takei and K. Iwata: J. Mater. Res. 24 (2009) 3503-3509.

17) H. Sato, K. Iwata, A. Tonegawa and Y. Nishi: J. Japan Inst. Metals 72 (2008) 526-531.

18) Y. Nishi, M. Uyama, H. Kawazu, H. Takei, K. Iwata, H. Kudoh and K. Mitsubayashi: Mater. Trans. 53 (2012) 1657-1664.

19) R. Christenhusz and L. Reimer: Z. Angew. Phys. 23 (1967) 396-404.

20) Y. Miyazawa, M. Uyama, S. Ishii, M. Kanda and Y. Nishi: Mater. Trans. 54 (2013) 1166-1170.

21) T. Nishida and E. Yasuda: Evaluation of Dynamic Properties of Ceramics (Ceramics no rikigaku tokusei hyouka in Japanese), (Nikkan Kogyo Shimbun LTD., Tokyo, 1986) pp. 50-51.

22) Y. Nishi, H. Sato, H. Takei and K. Iwata: J. Mater. Res. 24 (2009) 3503-3509.

23) H. Takei, M. Salvia, A. Vautrin, A. Tonegawa and Y. Nishi: Mate. Trans. 52 (2011) 734-739.

24) M. Kanda and Y. Nishi: Mater. Trans. 50 (2009) 177-181.

25) K. Iwata and Y. Nishi: Mater. Trans. 49 (2008) 2058-2062.

26) K. Iwata and Y. Nishi: Mater. Trans. 51 (2010) 121-127.

27) Y. Nishi, H. Kobayashi and M. Salvia: Mater. Trans. 48 (2007) 1924 1927.

28) N. Tsuchikura, M. C. Faudree and Y. Nishi: Mater. Trans. 54 (2013) 371-379.

29) Y. Nishi, H. Takei, K. Iwata, M. Salvia and A. Vautrin: Mater. Trans. 50 (2009) 2826-2832.

30) H. Takei, K. Iwata, M. Salvia, A. Vautrin and Y. Nishi: Mater. Trans. 51 (2010) 2259-2265.

31) A. Mizutani and Y. Nishi: Mater. Trans. 44 (2003) 1857-1860. 